\title{
Longitudinal analysis of an HLA-B $* 51$-restricted epitope in integrase reveals immune escape in early HIV-1 infection
}

\author{
Nicole Yager ${ }^{a}$, Nicola Robinson ${ }^{a}$, Helen Brown ${ }^{a}$, Peter Flanagan ${ }^{a}$, \\ John Frater ${ }^{\mathrm{a}, \mathrm{b}, \mathrm{c}}$, Sarah Fidler ${ }^{\mathrm{d}}$, Jonathan Weber ${ }^{\mathrm{d}}$, \\ Rodney Phillips ${ }^{a, b, c}$ the SPARTAC Trial Investigators
}

\begin{abstract}
Objective: To fully define cytotoxic T-lymphocyte (CTL) escape variants of an HLAB*51-restricted integrase epitope in early HIV-1 infection.

Design: Ninety-four longitudinally sampled acute/early HIV-1 subtype B-infected participants were assessed to determine HLA-B*51-restricted LPPVVAKEI (LI9) escape variants.

Methods: LI9 was sequenced at baseline and subsequent time points. Interferon- $\gamma$ (IFN $\gamma$ ) ELISpot assays were performed using serial log dilutions of variant LI9 peptides to determine the cellular response and functional avidity.

Results: There is a significant association between HLA-B*51 expression and an evolving LI9 sequence from baseline to year $1 \quad(P<0.0001)$. We detected that the V32I and P30X polymorphisms emerged within HLA-B $* 51^{+}$participants over time. Reversion of the P30S polymorphism was observed by year 1 in one HLA-B*51participant. LPPIIAKEI and LPSIVAKEI had significantly lower functional avidity compared with LPPVVAKEI and so may be less well recognized by LI9-specific CTLs; a positive IFN $\gamma$ response to IPSVVAKEI was rarely seen. Functional avidity to wild-type LI9 inversely correlated with viral load $\left(R^{2}=0.448, P=0.0485\right)$.
\end{abstract}

Conclusion: Our results provide support for the role of HLA-B*51-restricted CTLs and functional avidity in the control of early HIV-1 infection.

(C) 2013 Wolters Kluwer Health | Lippincott Williams \& Wilkins

AIDS 2013, 27:313-323

Keywords: cytotoxic T-lymphocyte escape, early HIV-1 infection, HLA-B51, integrase, longitudinal, vaccine

\section{Introduction}

The HIV-1-specific cytotoxic T-lymphocyte (CTL) response is important in the control of HIV-1 infection [1-6]. In order for an HIV-1-specific CTL vaccine to be efficacious, we must determine what constitutes an effective HIV-1-specific CTL response and how the virus has evolved to counteract this in terms of CTL escape [7-9]. Regions of the viral genome that are under structural and functional constraints can be identified by monitoring the different rates of reversion in the absence of immune pressure [10]. By studying HIV-1 epitopes restricted by human leukocyte antigen (HLA) alleles associated with slow progression to AIDS, we may gain a better understanding of how CTL escape and reversion influence viral fitness and progression.

\footnotetext{
${ }^{a}$ Nuffield Department of Clinical Medicine, Peter Medawar Building for Pathogen Research, University of Oxford, ${ }^{\text {b}}$ The James Martin 21 st Century School, Peter Medawar Building for Pathogen Research, 'Oxford NIHR Biomedical Research Centre, Oxford, and ${ }^{\mathrm{d}}$ Department of Medicine, Imperial College, London, UK.

Correspondence to Nicole Yager, Nuffield Department of Clinical Medicine, Peter Medawar Building for Pathogen Research, University of Oxford, Oxford OX1 3SY, UK.

E-mail: nicole.yager@stx.oxon.org

Received: 3 May 2012; revised: 7 October 2012; accepted: 16 October 2012.
} 
HLA-B*51 is known as a protective allele that is associated with slower progression to AIDS [11,12]. The three HLA-B*51-restricted CTL epitopes of most interest are NANPDCKTI (NI9, gag 325-333 p24, 193201), TAFTIPSI (TI8, pol 283-290, RT 128-135), and LPPVVAKEI (LI9, pol 743-751, integrase 28-36) [13]. LI9, situated in the N-terminal domain of integrase, was found to be the strongest binder to HLA-B*5101 [14]. A known interclade difference is present and can be clearly seen within the LI9 epitope at residue 31: the consensus is $31 \mathrm{~V}$ and $31 \mathrm{I}$ in HIV-1 subtypes B and C, respectively [15]. Cross-sectional sequencing data of chronically infected participants have indicated that I31V in LI9 is an HLA-B*51 negatively associated subtype B polymorphism; there has been positive selection of the escape mutation, which has not reverted following transmission and so has accumulated within the population to form the consensus [16]. After further analysing the transmission pair included in the Leslie et al. study, we perceived that the full LI9 epitope clonal sequencing data display more viral evolution than just at residue 31 . These polymorphisms need to be addressed, as they may have a greater impact on CTL escape.

We therefore aimed to fully define escape variants of the HLA-B*51-restricted LI9 epitope. As a viral load set point is achieved early in infection and is a predictor of progression to AIDS [17,18], it seems that the early immune response has a major impact on clinical outcome. By examining a large cohort of longitudinally sampled acute/early HIV-1 subtype B-infected participants, we can monitor precisely the effect of LI9-specific CTL pressure on an individual's viral quasispecies and the rapidity of reversion would provide insight into a mutation's viral fitness cost.

\section{Methods}

\section{Patients}

The HIV-1 subtype B-infected transmission pair (participants P32 and S32) has been previously described [16]. A total of $94 \mathrm{HIV}-1$ subtype B-infected participants were included in this analysis obtained through a study of acute HIV-1 infection at St Mary's Hospital (London, UK) and the Short Pulse AntiRetroviral Therapy At HIV seroconversion (SPARTAC, UK) trial. Criteria for acute HIV-1 infection were same as previously described $[19,20]$. Baseline samples were taken at the time of first presentation or trial enrolment, with samples obtained at sequential time points. HIV-1 subtypes were confirmed using the Recombinant Identification Program available on the Los Alamos HIV sequence database (http://www. hiv.lanl.gov/). HIV-1 nonsubtype B-infected participants from St Mary's Hospital and through the SPARTAC trial have also been analysed but are not included in the subtype B analysis. Peripheral blood mononuclear cells
(PBMCs) were isolated by centrifugation on a Lymphoprep (Axis-Shield, Oslo, Norway) gradient and cryopreserved.

This study was approved by the MREC, and written informed consent was obtained from all participants.

\section{Human leukocyte antigen typing}

HLA typing was performed using Dynal RELITM reverse sequence-specific oligonucleotide kits for the HLA-A, HLA-B, and HLA-C loci (Dynal Biotech, UK). The clinical data of $11 \mathrm{HLA}-\mathrm{B} * 5101^{+}$participants who were recruited are described in Table 1.

\section{Sequencing of viral RNA}

Viral RNA was extracted from plasma using the QIAamp Viral RNA Mini kit (Qiagen, Crawley, UK) according to the manufacturer's instructions. This was converted to cDNA using the SuperScript III kit (Invitrogen, Paisley, UK) and random decamers (Abgene, Epsom, UK). A cDNA fragment encoding integrase of the HIV-1 pol gene was amplified using nested PCR with the following primers: nest I primers 7F: $5^{\prime}$-AATTAGG AAAAGCAGGATATGT-TACTG- $3^{\prime}$ and $5^{\prime}$-CACTAG GCAAAGGTGGCTTTATC-3', or 5'-ACTCCATC CTG-ATAAATGGACAG- $3^{\prime}$ and 7R: $5^{\prime}$-AGTTTGTA TGTCTGTTGCTATTATGTCTAC-3'; nest II primers $7 \mathrm{~F}$ and $7 \mathrm{R}$. PCR products were purified using the QIAquick gel extraction kit (Qiagen) and either directly population sequenced or cloned using a TOPO TA cloning kit (Invitrogen). All sequencing was performed with the ABI Big Dye terminator sequencing kit (Applied Biosystems, UK) using PCR primers 7F or 7R. Sequences were aligned manually using Se-Al (University of Oxford, UK) software. Longitudinal viral sequences were verified by phylogenetic analysis using Phylogenetic inferences using Maximum Likelihood (PhyML) and the general time reversible model of evolution [21].

\section{Interferon- $\gamma$ ELISpot assay}

Interferon- $\gamma$ (IFN $\gamma$ ) ELISpot assays were performed using optimally defined epitopes with the number of thawed PBMCs per well ranging from 45000 to 70000 . In brief, 96-well polyvinylidene fluoride membrane plates (Millipore, Watford, UK) were precoated with capture anti-IFNy mAb (Mabtech, Nacka Strand, Sweden) overnight at $4^{\circ} \mathrm{C}$. Peptides at either $1 \mu \mathrm{g} / \mathrm{ml}$ or serial log dilutions used were as follows: TI8, NI9, LI9, and variant LI9 peptides (LPPIVAKEI, LPPIIAKEI, LPPVIAKEI, IPPVVAKEI, IPSVVAKEI, and LPSIVAKEI). Test wells were performed in duplicate when PBMCs were available. Negative control wells containing PBMCs and R10, and positive control wells containing PBMCs and PHA were run in duplicate. Plates were incubated for $16 \mathrm{~h}$ at $37^{\circ} \mathrm{C}$ and $5 \% \mathrm{CO}_{2}$, and developed according to the manufacturer's instructions. The number of spots per well were quantified using the AID ELISpot 


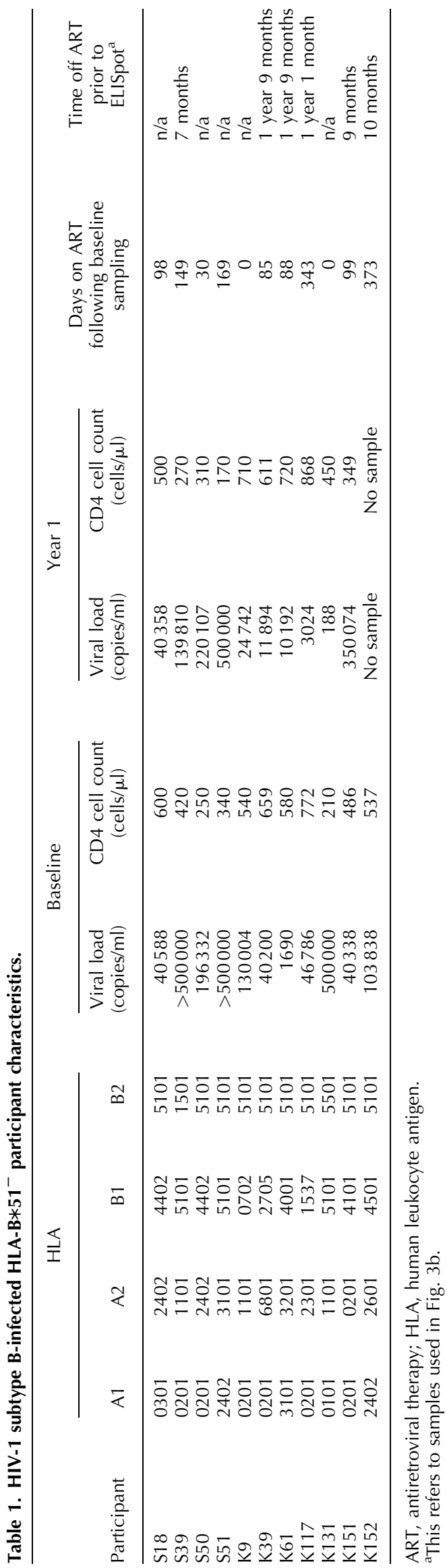

automated plate reader (AID GmbH, Straßberg, Germany) and were multiplied to spot-forming units (SFU) $/ 10^{6}$ PBMCs. Background IFN $\gamma$ release from PBMCs in negative control wells was subtracted from all test wells. A positive result required the following criteria: at least three-fold greater than the background; a positive response to PHA; and tested wells had more than $50 \mathrm{SFU} / 10^{6}$ PBMCs following subtraction of background.

Functional avidity was assessed by performing limiting peptide dilutions $(1-0.0001 \mu \mathrm{mol} / \mathrm{l})$ and determining the peptide concentration required to induce $50 \%$ of the peak IFN $\gamma$ response.

\section{Statistical analysis}

Data were analysed using GraphPad Prism software. Fisher's exact tests, unpaired t-tests and the MannWhitney $U$-test were used. Correlation analysis was performed using Pearson's correlation test. A value of $P$ less than 0.05 was considered statistically significant.

\section{Results}

\section{Viral evolution of the HLA-B $* 51$-restricted LI9 epitope in a transmission pair}

The full LI9 epitope clonal sequencing data of a horizontal transmission pair are shown in Table 2. The chronically infected HLA-B $* 51^{+}$donor had the LPPIIAKEI variant circulating at the first time point. Eighteen months later, the V31I polymorphism had reverted to consensus; three variants were detected after a further 3 months: IPPVIAKEI, LPPVIAKEI, and LPAVIAKEI. The LPPVIAKEI variant was detected in the earliest sample of the HLA-B*51- recipient; this persisted for at least 48 days, with reversion to consensus detected 6 months later.

\section{HLA-B $* 51$-associated selection pressure on LI9 in early HIV-1 infection}

Direct PCR population sequencing was performed on longitudinal samples from 94 acute/early HIV-1 subtype B-infected participants enabling intrahost HIV-1 evolution to be monitored. The amplified region of HIV-1 pol encoding integrase contained the HLA-B*51restricted epitope LI9. Figure 1a shows that four of 10 HLA-B $* 51^{+}$participants had a change in dominating LI9 variant from baseline to year 1. Specifically, these were LPPVVAKEI $\rightarrow$ LPPVIAKEI; LPPIVAKEI $\rightarrow$ LPPVIAKEI; LPPIVAKEI $\rightarrow$ LPPIIAKEI; and LPPIIAKEI $\rightarrow$ LPSIVAKEI. No change in the dominating variant was detected for the 83 HLA-B*51participants. There is a statistically significant association between HLA-B*5101 expression and an evolving LI9 sequence from baseline to year $1(P<0.0001$, Fisher's exact test). One HLA-B* $51^{+}$participant was not 
Table 2. Clonal sequencing of the LI9 epitope from an HLA-B $* 51^{+} / \mathrm{HLA}-\mathrm{B} * 51^{-}$transmitter pair.

\begin{tabular}{|c|c|c|c|c|c|c|c|c|c|c|c|}
\hline & Time point & $\mathrm{L}$ & $P$ & $P$ & $\mathrm{~V}$ & $\mathrm{~V}$ & A & K & $\mathrm{E}$ & 1 & Number of clones \\
\hline \multicolumn{12}{|c|}{$\mathrm{B} 51^{+}$donor } \\
\hline \multirow[t]{5}{*}{ P32 } & 21/09/1999 & - & - & - & I & I & - & - & - & - & $22 / 22$ \\
\hline & 08/03/2001 & - & - & - & - & I & - & - & - & - & $11 / 11$ \\
\hline & $01 / 06 / 2001$ & I & - & - & - & 1 & - & - & - & - & 9/18 \\
\hline & & - & - & - & - & I & - & - & - & - & $7 / 18$ \\
\hline & & - & - & A & - & I & - & - & - & - & $2 / 18$ \\
\hline \multicolumn{12}{|c|}{ B51- recipient } \\
\hline \multirow[t]{3}{*}{ S32 } & $21 / 08 / 2001$ & - & - & - & - & I & - & - & - & - & $12 / 12$ \\
\hline & 08/10/2001 & - & - & - & - & 1 & - & - & - & - & $16 / 16$ \\
\hline & $04 / 04 / 2002$ & - & - & - & - & - & - & - & - & - & $23 / 23$ \\
\hline
\end{tabular}

sampled at year 1 and so was not included in this analysis; however, LPPVVAKEI and LPPVIAKEI were dominating at baseline and week 96, respectively.

In terms of HLA-associated sequence polymorphisms in this cohort, the V32I polymorphism was found in participants expressing HLA-B*51 at baseline and year 1 $(P=0.0105$ and 0.0001 , respectively); it was not present in the HLA-B* $51^{-}$subjects. As baseline samples are within 6 months of transmission, V32I may either have been transmitted or was selected prior to sampling. Also of note, further time points were sequenced in participant K61, showing that whereas LPPVVAKEI dominated at baseline, year 1, and year 2, LPPVIAKEI emerged as the dominant variant at year 3. At baseline, there was no evidence of an association between L28I, P30X, or V31I and HLA-B*51 expression $(P=0.505$, 1.0 , and 0.257 , respectively); this was still the case at year 1 $(P=0.505,0.292$, and 0.696 , respectively, Fisher's exact test). Therefore, the previously branded negative HLA-B*51 association I31V [16] was not found within this early HIV-1-infected cohort; HLA-B* $51^{+}$participants did not significantly select for the I31V polymorphism over 1 year (Fig. 1b).

To determine how HLA-B*51 expression with a mutating LI9 epitope over 1 year would produce such a strong association (Fig. 1a), we postulated that residue 31 of integrase may not be an important factor in terms of early CTL escape. The mean proportion of participants with a LI9 variant other than LPPVVAKEI or LPPIVAKEI was significantly greater in HLA-B*51 ${ }^{+}$ participants compared with HLA-B $* 51^{-}$participants at year $1(P<0.0006$; Fig. $1 c)$.

An analysis of the upstream and downstream residues of LI9 in integrase was undertaken. No clear compensatory mutations could be determined (data not shown).

\section{TI8 and LI9 are the HLA-B $* 51$-restricted immunodominant epitopes in early HIV-1 infection}

Of the five HLA-B* $51^{+}$participants with IFN $\gamma$ ELISpot data at both baseline and week 24 , all made a response to LPPVVAKEI, four made a response to TAFTIPSI at baseline and three at week 24, only one had a NANPDCKTI response at week 0 , and one participant had a NANPDCKTI response at week 24. LI9 was the most frequently targeted HLA-B*51 epitope during early HIV-1 infection. Depending on the participant and the time point of infection, either TI8 or LI9 was the immunodominant response (Fig. 2a).

\section{LI9-P30S variants produce significantly reduced interferon- $\gamma$ responses}

Mutations detected in the HLA-B $* 51^{+}$participants imply that the LI9 epitope is under immune pressure. To assess the LI9-specific CTL response, IFN $\gamma$ ELISpot assays were carried out using HLA-B* $51^{+}$participant PBMCs and LI9 variant peptides. We used serial log dilutions of peptide concentrations for a subset of participants to represent a more physiological estimate of epitope counts on a cell, as the presence of $1 \mu \mathrm{mol} / 1$ peptide may not represent a natural response [22].

The percentage of participants with a positive IFN $\gamma$ response and the magnitude of the response to LI9 and its variants generally increased over time (Fig. 2b). A positive response to IPSVVAKEI was rarely seen, and generally weak even when observed; $10^{-6}$ and $10^{-7} \mathrm{~mol} / 1$ IPSVVAKEI produce a positive mean IFN $\gamma$ response (92 and $96 \mathrm{SFU} / 10^{6} \mathrm{PBMCs}$, respectively) only at year 2. The IFN $\gamma$ response to LPSIVAKEI at year 2 was significantly lower than wild-type LI9 at $10^{-6}, 10^{-7}$, and $10^{-8} \mathrm{~mol} / \mathrm{l}$ peptide $(P=0.0031,0.0011$, and 0.0134 , respectively); the mean IFN $\gamma$ response to LPSIVAKEI was less than $500 \mathrm{SFU} / 10^{6}$ PBMCs at all time points.

\section{Higher functional avidity to LPPVVAKEI correlates with a lower viral load}

Functional avidity may be assessed by determining the $\mathrm{EC}_{50}$ value, which is the peptide concentration that induces $50 \%$ of the peak IFNy response (Fig. 3). Although it appears that LPPVVAKEI has the highest functional avidity, there is no significant difference between $\mathrm{EC}_{50}$ values for wild-type LI9 and LPPIVAKEI, LPPVIAKEI, or IPPVVAKEI. The variants LPPIIAKEI 
(a)

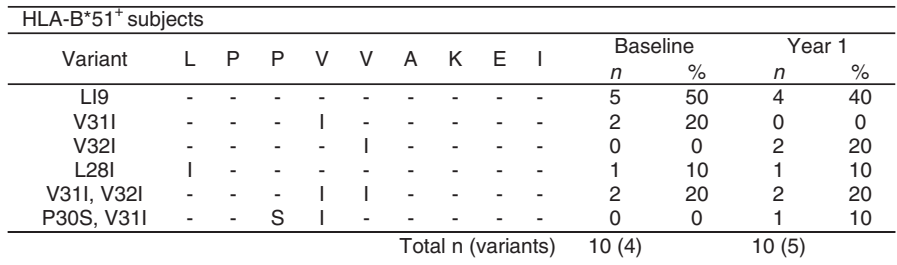

\begin{tabular}{|c|c|c|c|c|c|c|c|c|c|c|c|c|c|}
\hline \multicolumn{14}{|c|}{ HLA-B* $51^{-}$subjects } \\
\hline \multirow{2}{*}{ Variant } & \multirow{2}{*}{$\mathrm{L}$} & \multirow{2}{*}{$\mathrm{P}$} & \multirow{2}{*}{$\mathrm{P}$} & \multirow{2}{*}{ V } & \multirow{2}{*}{ V } & \multirow{2}{*}{ A } & \multirow{2}{*}{$\mathrm{K}$} & \multirow{2}{*}{ E } & \multirow{2}{*}{ I } & \multicolumn{2}{|c|}{ Baseline } & \multicolumn{2}{|c|}{ Year 1} \\
\hline & & & & & & & & & & $n$ & $\%$ & $n$ & $\%$ \\
\hline LI9 & - & - & - & - & - & - & - & - & - & 56 & 67.5 & 56 & 67.5 \\
\hline V31I & - & - & - & I & - & - & - & - & - & 19 & 22.9 & 19 & 22.9 \\
\hline L28I & I & - & - & - & - & - & - & - & - & 4 & 4.8 & 4 & 4.8 \\
\hline K34R & - & - & - & - & - & - & $\mathrm{R}$ & - & - & 2 & 2.4 & 2 & 2.4 \\
\hline P30A & - & - & A & - & - & - & - & - & - & 1 & 1.2 & 1 & 1.2 \\
\hline L28I, P30S & I & - & $\mathrm{S}$ & - & - & - & - & - & - & 1 & 1.2 & 1 & 1.2 \\
\hline
\end{tabular}

(b)

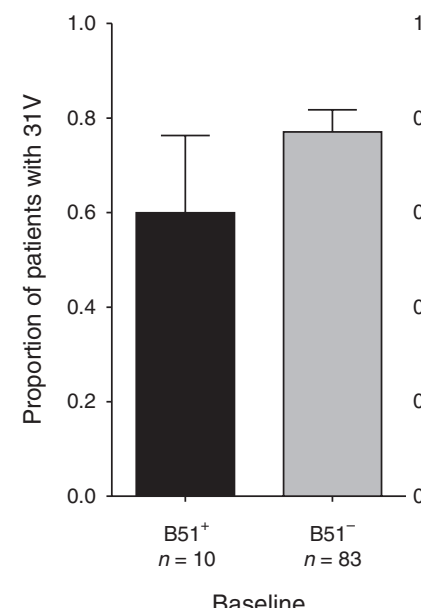

Baseline (c)

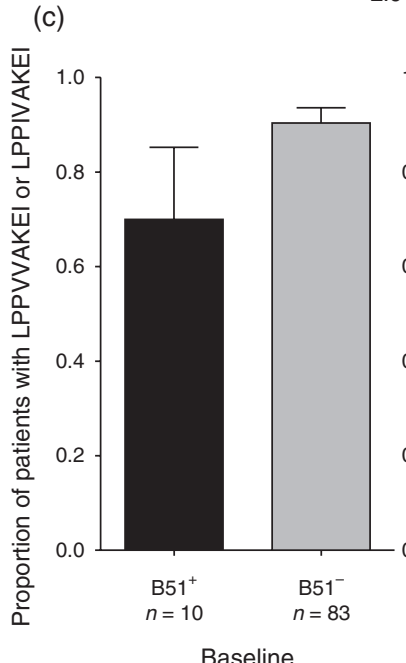

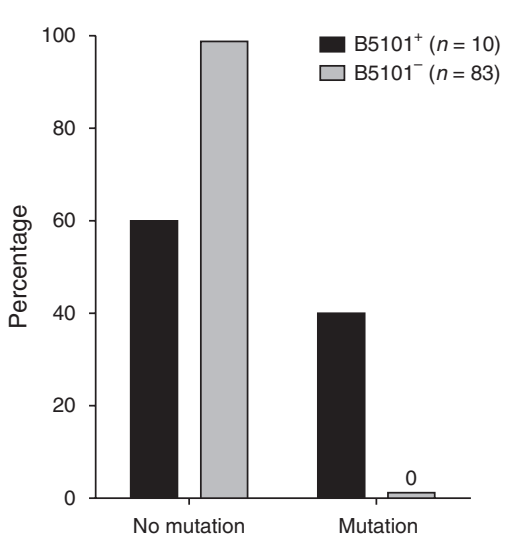

LI9 from baseline to year 1

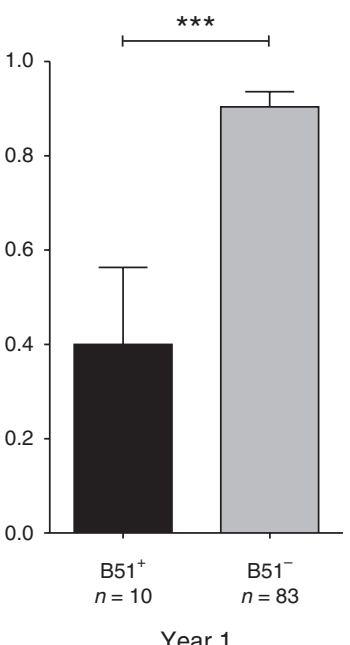

Fig. 1. Longitudinal sequencing data of HIV-1 subtype B LI9 variants with respect to HLA-B $* 51$ expression. (a) Change in the dominating LI9 variant from baseline to year 1 with respect to HLA-B*51 expression. A mutating LI9 sequence was associated with HLA-B*51 expression $(P<0.0001$, Fisher's exact test). (b) Proportion of subtype B 31V variants. The SEM is shown; there is no significant difference between HLA-B*51 expression and 31V at baseline or year 1. (c) Proportion of subtype B LPPVVAKEI or LPPIVAKEI variants. The SEM is shown; there is a significant difference between expressing HLA-B*51 and having LPPVVAKEI or LPPIVAKEI by year $1(P<0.0006$, Fisher's exact test). HLA, human leukocyte antigen.

and LPSIVAKEI have significantly larger $\mathrm{EC}_{50}$ values than wild-type LI9 ( $P=0.0039$ and 0.0110 , respectively); IPSVVAKEI was omitted from this analysis because only one $\mathrm{EC}_{50}$ value $\left(1.847 \times 10^{-6} \mathrm{~mol} / \mathrm{l}\right)$ was available for participant $\mathrm{K} 9$ at year 2. In terms of clinical outcome, there was a correlation between viral load and $\mathrm{EC}_{50}$ for wild-type LI9 $\left(R^{2}=0.448, P=0.0485\right)$. Those participants with a higher functional avidity to LPPVVAKEI correlated with a lower viral load.

\section{Emergence of $\mathrm{P} 30 \mathrm{X}$ in $\mathrm{HLA}-\mathrm{B} * 51^{+}$participants}

P30X emerged over time in HLA-B $* 51^{+}$participants S18, S50, and K151 (Table 3).

\section{Participant 518}

Clonal sequencing of participant S18's baseline and year 1 samples demonstrated that whereas LPPIIAKEI was the dominating variant at baseline, LPSIVAKEI was found in
10 of 30 clones, LPHIVAKEI in four of 30 clones, and wild-type LI9 in two of 30 clones. By year 1, LPSIVAKEI and LPHIVAKEI were the only variants observed; LPSIVAKEI was still dominant at year 2 as determined by direct PCR population sequencing.

\section{Participant 550}

Direct PCR population sequencing was carried out on participant S50 samples. IPPVVAKEI was found at baseline, a mixture of IPPVVAKEI and IPSVVAKEI at year 1, with the former dominating, and both IPSVVAKEI and IPAVVAKEI were observed in equal amounts at year 2 .

\section{Participant K151}

Clonal sequencing data were obtained at three time points for participant K151. At baseline, all 31 clonal sequences were of the wild-type LI9 variant. By year 1, 26 of 

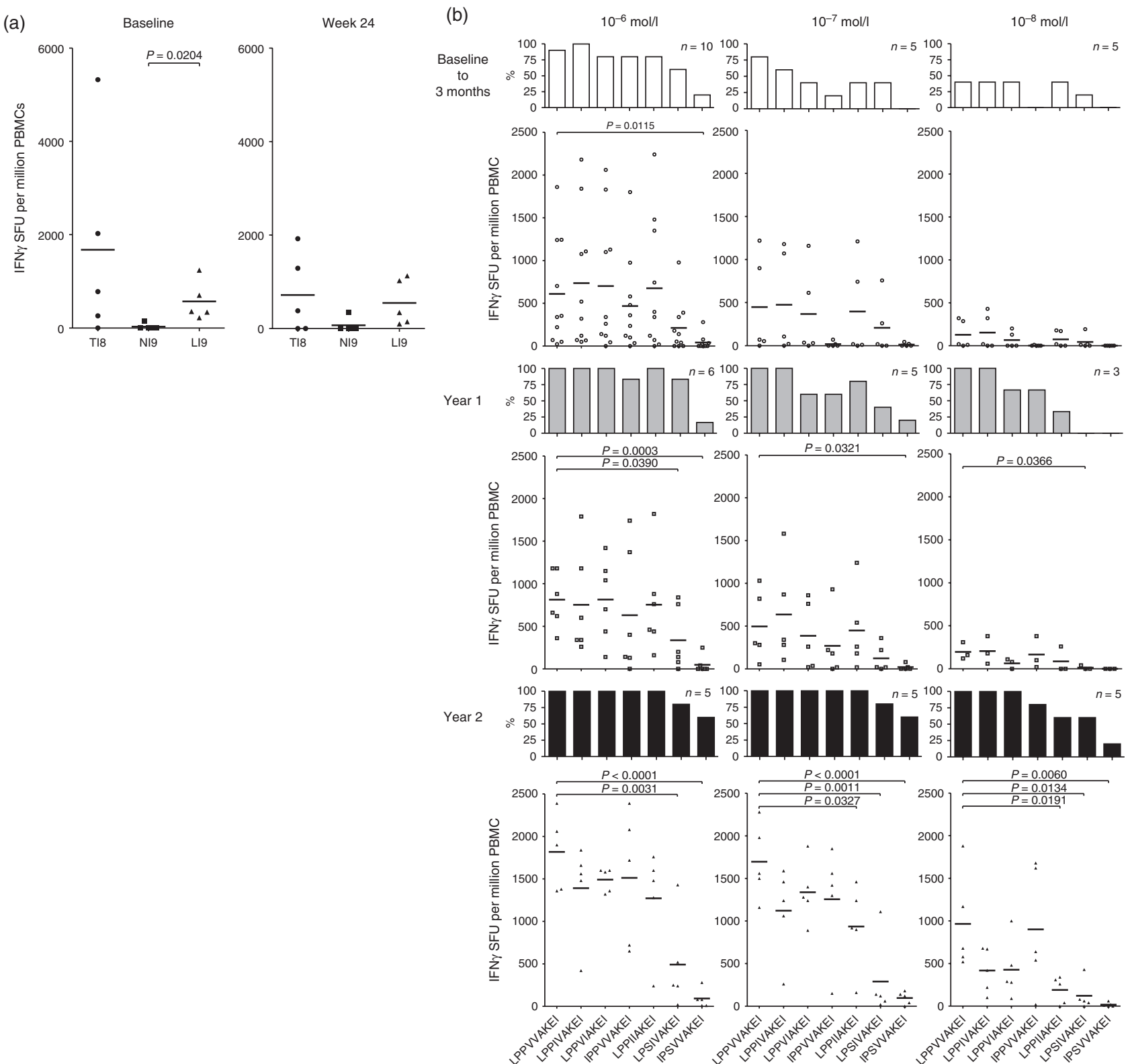

Fig. 2. Longitudinal analysis of HLA-B*51-restricted CTL responses. (a) HLA-B*51-restricted CTL responses during early HIV-1 infection. The magnitude of the response in the presence of $10^{-6} \mathrm{~mol} / \mathrm{I}$ TAFTIPSI, LPPVVAKEI and NANPDCKTI peptides is shown at baseline and week 24. (b) Longitudinal analysis of HLA-B*51-restricted LI9-specific CTL responses. The percentage of HIV-1 subtype B-infected HLA-B $* 51^{-}$participants with a positive IFN $\gamma$ ELISpot response $\left(>50\right.$ spot-forming units $/ 10^{6}$ peripheral blood mononuclear cells) and the magnitude of the response in the presence of serial log dilutions of LI9 and variants is shown at baseline to 3 months, year 1 and 2. $P$ values were calculated using the unpaired $t$-test. CTL, cytotoxic T lymphocyte; HLA, human leukocyte antigen; IFN, interferon; PBMC, peripheral blood mononuclear cell; SFU, spot-forming unit.

26 clones had the V32I mutation and 27 of 29 clones had the V32I mutation at year 2, but of particular interest, four of 29 clones were of the LPSVIAKEI variant. The P30S mutation had emerged between year 1 and 2, following the V32I mutation.

An IFN $\gamma$ ELISpot was performed on PBMCs from participant K151 at year 1 using LI9 peptide variants titrated at serial log dilutions. A positive IFN $\gamma$ response was generated against $10^{-6}$ to $10^{-8} \mathrm{~mol} / 1$ LPPVVAKEI. A positive response (140 SFU $\left./ 10^{6} \mathrm{PBMCs}\right)$ to LPPVIAKEI was made only at a peptide concentration of $10^{-6} \mathrm{~mol} / \mathrm{l}$. Although the LPSVIAKEI peptide was not included in our ELISpot peptide panel, a weak IFN $\gamma$ response (80 SFU $/ 10^{6} \mathrm{PBMCs}$ ) was made to $10^{-6} \mathrm{~mol} / 1$ LPSIVAKEI and there was no positive response to IPSVVAKEI at any concentration assayed. These data support the clonal sequencing results: if wild-type LI9 was 
(a)

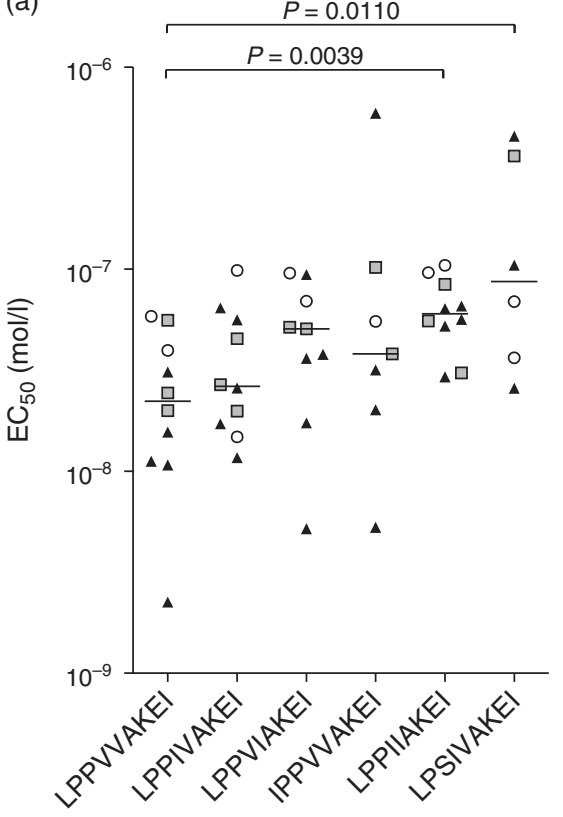

(b)

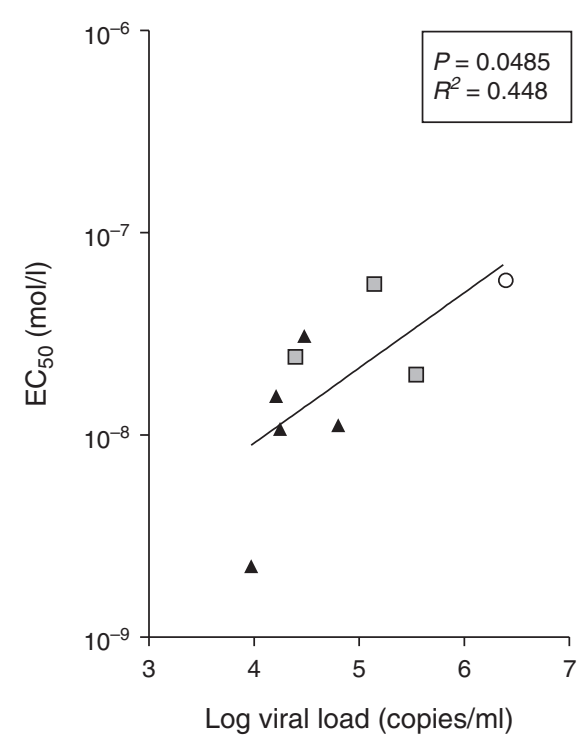

- Baseline - 3 months
- Year 1
\ Year 2

Fig. 3. CTL functional avidity. (a) Functional avidity of HLA-B*51-restricted LI9-specific CTL. PBMCs from participants with positive responses were analysed. $\mathrm{EC}_{50}$ values were only included if the $R^{2}>0.8$ and the curve had converged. The median is shown as a horizontal bar for each LI9 variant; $P$ values were calculated using the Mann-Whitney $U$-test. (b) Functional avidity of HLA-B*51-restricted LPPVVAKEI versus viral load. No participant was on ART at the time of analysis; participants who had previously been on a course of ART, were off therapy for at least 7 months (Table 1). Correlation analysis was performed using Pearson's correlation test. ART, antiretroviral therapy; CTL, cytotoxic T lymphocyte; HLA, human leukocyte antigen; PBMC, peripheral blood mononuclear cell.

transmitted to participant K151, the strong CTL response has driven escape to the simplest variant, V32I. This further mutated into LPSVIAKEI, which we predict would produce a similar IFN $\gamma$ response as IPSVVAKEI or LPSIVAKEI.

\section{Reversion of P30S in an $\mathrm{HLA}-\mathrm{B} * 51^{-}$participant} Clonal sequencing data were obtained at three time points for participant OX113 (HLA-A*0201, HLA-A*0301, HLA-B*0702, and HLA-B*4402) (Table 3). At baseline, 19 of 20 clones had the IPSVVAKEI variant with one clone having an additional K34E polymorphism. The P30S mutation had started to revert back to consensus (five of 32 clones) by year 1 and all 32 clonal sequences were $30 \mathrm{P}$ by year 2 . The P30S mutation had completely reverted within 2 years, whereas the L28I polymorphism remained.

An IFN $\gamma$ ELISpot assay was carried out on month 3 and year 1 PBMCs from participant OX113. No positive response at $10^{-6} \mathrm{~mol} / 1$ was observed against LI9 or variant peptides at both time points; a strong positive response to PHA was observed.
The P30S reversion was also observed in participant K38 (HLA-A*0201 homozygous, HLA-B*1501, and HLA-

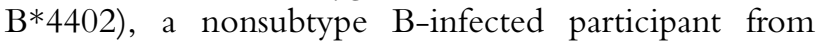
the SPARTAC trial. This HLA-B*51- participant had the LPSVVAKEI variant dominating at baseline and month 6 as determined by direct PCR population sequencing; however, 30P was dominant at year 1 (data not shown).

\section{Discussion}

Here we aimed to define fully the HLA-B*51-restricted LI9 variants that evade CTL recognition. Longitudinal sequencing of HLA-B* $51^{+}$acute/early HIV-1-infected participants revealed the emergence of V32I and P30X mutations. Reversion of the V32I and P30S polymorphisms in HLA-B*51- participants within a year indicates that there may be an associated fitness cost conferred by these polymorphisms. Reduced replication capacity of $\mathrm{HIV}_{\mathrm{NL4-3}}$ recombinant viruses that encode Gag-protease [23] and RT-integrase [24] sequences from elite controllers suggests that CTL escape mutations in 
Table 3. Emergence of $\mathrm{P} 30 \mathrm{X}$ in $\mathrm{HLA}-\mathrm{B} * 51^{+}$participants and reversion of $\mathrm{P} 30 \mathrm{~S}$ in an $\mathrm{HLA}-\mathrm{B} * 51^{-}$participant.

\begin{tabular}{|c|c|c|c|c|c|c|c|c|c|c|c|}
\hline & Time point & $\mathrm{L}$ & $P$ & $P$ & V & V & A & K & $\mathrm{E}$ & I & Number of clones \\
\hline \multicolumn{12}{|c|}{$\mathrm{B} 51^{+}$participant } \\
\hline \multirow[t]{8}{*}{ S18 } & Baseline & - & - & - & I & I & - & - & - & - & $13 / 30$ \\
\hline & & - & - & $\mathrm{S}$ & I & - & - & - & - & - & $10 / 30$ \\
\hline & & - & - & $\mathrm{H}$ & I & - & - & - & - & - & $4 / 30$ \\
\hline & & - & - & - & - & - & - & - & - & - & $2 / 30$ \\
\hline & & - & - & - & - & - & - & $\mathrm{R}$ & - & - & $1 / 30$ \\
\hline & Year 1 & - & - & $\mathrm{S}$ & I & - & - & - & - & - & $24 / 30$ \\
\hline & & - & - & $\mathrm{H}$ & I & - & - & - & - & - & $6 / 30$ \\
\hline & Year 2 & - & - & $\mathrm{S}$ & i & - & - & - & - & - & Population sequencing \\
\hline \multirow{5}{*}{ S50 } & Baseline & I & - & - & - & _- & - & - & - & - & Population sequencing \\
\hline & Year 1 & I & - & - & - & - & - & - & - & - & Population sequencing \\
\hline & & I & - & S & - & - & - & - & - & - & \\
\hline & Year 2 & I & - & $\mathrm{S}$ & - & _- & - & - & - & - & Population sequencing \\
\hline & & I & - & A & - & - & - & - & - & - & \\
\hline \multirow[t]{8}{*}{ K151 } & Baseline & - & - & - & - & - & - & - & - & - & $31 / 31$ \\
\hline & Year 1 & - & - & - & - & I & - & - & - & - & $25 / 26$ \\
\hline & & $\mathrm{P}$ & - & - & - & 1 & - & - & - & - & $1 / 26$ \\
\hline & Year 2 & - & - & - & - & i & - & - & - & - & $22 / 29$ \\
\hline & & - & - & $S$ & - & 1 & - & - & - & - & $4 / 29$ \\
\hline & & - & - & - & $A$ & 1 & - & - & - & - & $1 / 29$ \\
\hline & & - & - & - & - & M & - & - & - & - & $1 / 29$ \\
\hline & & - & - & - & - & - & - & - & Q & - & $1 / 29$ \\
\hline \multicolumn{12}{|c|}{ B51- participant } \\
\hline \multirow[t]{8}{*}{ Ox113 } & Baseline & I & - & S & - & - & - & - & - & - & $19 / 20$ \\
\hline & & I & - & S & - & - & - & E & - & - & $1 / 20$ \\
\hline & Year 1 & I & - & $S$ & - & - & - & - & - & - & $27 / 32$ \\
\hline & & I & - & - & - & - & - & - & - & - & 4/32 \\
\hline & & I & - & - & A & - & - & - & - & - & $1 / 32$ \\
\hline & Year 2 & I & - & - & - & - & - & - & - & - & $30 / 32$ \\
\hline & & I & S & - & - & - & - & - & - & - & $1 / 32$ \\
\hline & & i & - & - & - & - & - & - & - & $\mathrm{V}$ & $1 / 32$ \\
\hline
\end{tabular}

these regions impact on viral fitness and, therefore, may contribute to the elite controller phenotype.

I31V was not found to be negatively associated with HLA-B*51 expression in early HIV-1 infection. Although LPPIVAKEI did disappear over time in our HLA-B* $51^{+}$participants, there was no increase in LPPVVAKEI. Instead, the emergence of LPPVIAKEI, LPPIIAKEI, and LPSIVAKEI was observed, with a significant association between HLA-B*51 expression and LI9 mutation within 1 year. The I31V negative association [16] and the fact that the percentage of I31V correlates with HLA-B*51 prevalence [25] was based on cross-sectional sequencing data and was irrespective of other LI9 polymorphisms. So, although the I31V variant may be present in populations with a greater prevalence of HLA-B*51, the positive IFNy response to both the LPPVVAKEI and LPPIVAKEI peptides in this study indicates that it is not the I31V polymorphism alone that is driving LI9 escape. Supporting this finding, multiple pieces of evidence demonstrate that viral lineage founder effects confound the interpretation of the $\mathrm{I} 31 \mathrm{~V}$ negative association data [26]. In addition, we did not observe the emergence of the L28I polymorphism in our early HIV-1-infected participants as previously noted in a cross-sectional study of HLA$\mathrm{B} * 51^{+}$participants infected with HIV-1 for 10 years [13].
As many of the participants analysed in this study were on antiretroviral therapy (ART) for varying durations, the question beckons whether this could have an effect on LI9 escape? We would expect ART to influence the rate of CTL escape by slowing it down: ART reduces viral load, thereby lowering the level of viral replication, which is vital for enabling CTL escape variants to emerge. As we have shown that LI9 escape occurs early in HIV-1 infection in the presence of ART, we predict that in its absence, escape from this immune pressure may be faster; however, given the small numbers in each trial arm we were unable to assess this.

When functional avidity was assessed, LPPIVAKEI, LPPVIAKEI, and IPPVVAKEI peptides generated $\mathrm{EC}_{50}$ values that were not significantly different from those generated by LPPVVAKEI. Only responses to LPPIIAKEI and LPSIVAKEI had greater $\mathrm{EC}_{50}$ values than wild-type LI9, implying that they have a significant lower functional avidity and may be less well recognized by LI9-specific CTLs. Calculating an $\mathrm{EC}_{50}$ value for IPSVVAKEI was limited by the lack of positive IFN $\gamma$ responses to this peptide. The overall $\mathrm{EC}_{50}$ values are lower than those reported against HLA-B*27 epitopes $[27,28]$; it appears there is a stronger functional avidity to LI9 and its variants. 
Functional avidity to wild-type LI9 inversely correlated with viral load, which in turn is a predictor of progression to AIDS [17,18], suggesting that strong CTL recognition of LI9 may affect clinical outcome. It would therefore be interesting to determine whether the same was true for TI8-specific and NI9-specific CTLs. Zhang et al. [13] observed a significantly higher viral load when more than one HLA-B*51-restricted epitope had mutated. Perhaps for sustained control of HIV infection, functional avidity to multiple epitopes correlates with viral load, providing a possible explanation as to why HLA-B*51 is associated with slower progression to AIDS.

Participants studied in our analysis who had previously been on ART were off treatment for at least 7 months at the time of IFN $\gamma$ ELISpot. However, the SPARTAC trial found that participants who received ART for 48 weeks following baseline had a $0.44(0.25,0.64) \log _{10}$ copies $/ \mathrm{ml}$ reduction in viral load 36 weeks after stopping treatment compared with participants who had not received ART [29]. As two HLA-B*51 $1^{+}$participants received ART at baseline for a 48-week period and are included in Fig. 3b; this should be taken into consideration, although both were off ART for at least 10 months at the time of IFN $\gamma$ ELISpot.

LI9 is predicted to be an overlapping epitope with the A2 supertype-binding epitopes MASDFNLPPV (integrase 22-31) and RAMASDFNL (integrase 2028) [15]. Apart from the reversion in participant OX113, no change in LI9 was observed in the 55 HLA-A*0201 ${ }^{+}$, HLA-B $* 51^{-}$participants in this study. However, IFNy and cytotoxic responses to these peptides have only been produced by memory resting cells following in-vitro expansion with $10^{-5} \mathrm{~mol} / \mathrm{l}$ peptide stimulation and interleukin-2; no memory effector $\mathrm{CD} 8^{+}$response was detected in an IFN $\gamma$ ELISpot assay [30].

In addition, the LI9 epitope has been found to be recognized by the B7 supertype alleles HLA-B*4201, HLA-B*0702 [31], and HLA-B*0705 [32]. In this current study, only one participant was HLA-B*4201 ${ }^{+}$ and had the subtype $\mathrm{B}$ consensus LI9 sequence at baseline, year 1 , and year 2 . Of the $22 \mathrm{HLA}-\mathrm{B} * 0702^{+}$participants in this early HIV-1-infected cohort, no change in LI9 was observed except the reversion found in participant OX113. However, we found no IFN $\gamma$ response by participant OX113 to LI9 or variant peptides.

We suggest that the main factor in HLA-B*51-associated LI9 escape is the P30X polymorphism. Escape of CTL recognition at position 3 of an epitope is also observed in the HLA-B*57/5801-restricted epitope TSTLQEQIAW (gag 240-249), resulting in the T242N mutation. Similarly to the reversion we have seen with the P30S mutation in LI9, reversion of the T242N mutation in an HIV-1-infected HLA-B $* 57^{-} / 5801^{-}$participant was observed at an early time point of infection [33].
To conclude, our data indicate that HLA-B*51 pressure selects for a multitude of LI9 variants that may ultimately lead to LI9 CTL escape, although resulting in a virus with a reduced replication capacity. We propose that LI9 would be a good candidate to be included in an HIV-1 CTL vaccine, as there is generally a positive response to the most frequent subtype B LI9 variants of a strong magnitude, plus it is difficult to gain full LI9 escape in early HIV-1 infection. If reversion of P30S was to occur in all HLA-B* $51^{-}$participants, LI9 and variants that induce strong CTL responses would persist in circulating viral sequences and so may prove beneficial in HIV-1 vaccine design.

\section{Acknowledgements}

We would like to thank all study participants and staff of St Mary's Hospital, Jefferiss Wing clinic, and all the participants and staff at all the sites participating in the SPARTAC trial.

Author contributions: R.P. conceived the study; N.Y., J.F., and R.P. designed the study; N.Y., N.R., H.B., and P.F. performed all assays; N.Y. analysed the data; N.Y. wrote the paper; R.P., S.F., and J.W. contributed the samples and subject information.

SPARTAC Trial Investigators: Trial Steering Committee: A. Breckenridge (Chair), P. Clayden, C. Conlon, F. Conradie, J. Kaldor*, F. Maggiolo, F. Ssali. Country Principal Investigators: D.A. Cooper, P. Kaleebu, G. Ramjee, M. Schechter, G. Tambussi, J. Weber. Trial Physician: S. Fidler. Trial Statistician: A. Babiker. Data and Safety Monitoring Committee: T. Peto (Chair), A. McLaren (in memoriam), V. Beral, G. Chene, J. Hakim. Co-ordinating Trial Centre: MRC Clinical Trials Unit, London (A. Babiker, K. Porter, M. Thomason, F. Ewings, M. Gabriel, D. Johnson, K. Thompson, A. Cursley*, K. Donegan*, E. Fossey*, P. Kelleher*, K. Lee*, B. Murphy*, D. Nock*). Central Immunology Laboratories and Repositories: The Peter Medawar Building for Pathogen Research, University of Oxford, UK (R. Phillips, J. Frater, L. Ohm Laursen*, N. Robinson, P. Goulder, H. Brown). Central Virology Laboratories and Repositories: Jefferiss Trust Laboratories, Imperial College, London, UK (M. McClure, D. Bonsall*, O. Erlwein*, A. Helander*, S. Kaye, M. Robinson, L. Cook*, G. Adcock*, P. Ahmed*). Clinical Endpoint Review Committee: N. Paton, S. Fidler. Investigators and Staff at Participating Sites: Australia: St Vincent's Hospital, Sydney (A. Kelleher), Northside Clinic, Melbourne (R. Moore), East Sydney Doctors, Sydney (R. McFarlane), Prahran Market Clinic, Melbourne (N. Roth), Taylor Square Private Clinic, Sydney (R. Finlayson), The Centre Clinic, Melbourne (B. Kiem Tee), Sexual Health Centre, Melbourne (T. Read), AIDS Medical Unit, 
Brisbane (M. Kelly), Burwood Rd Practice, Sydney (N. Doong), Holdsworth House Medical Practice, Sydney (M. Bloch), Aids Research Initiative, Sydney (C. Workman). Coordinating centre in Australia: Kirby Institute University of New South Wales, Sydney (P. Grey, D.A. Cooper, A. Kelleher, M. Law). Brazil: Projeto Praça Onze, Hospital Escola São Francisco de Assis, Universidade federal do Rio de Janeiro, Rio de Janeiro (M. Schechter, P. Gama, M. Mercon*, M. Barbosa de Souza, C. Beppu Yoshida, J.R. Grangeiro da Silva, A. Sampaio Amaral, D. Fernandes de Aguiar, M. de Fátima Melo, R. Quaresma Garrido). Italy: Ospedale San Raffaele, Milan (G. Tambussi, S. Nozza, M. Pogliaghi, S. Chiappetta, L. Della Torre, E. Gasparotto), Ospedale Lazzaro Spallanzani, Roma (G. D’Offizi, C. Vlassi, A. Corpolongo). South Africa: Cape Town: Desmond Tutu HIV Centre, Institute of Infectious Diseases, Cape Town (R. Wood, J. Pitt, C. Orrell, F. Cilliers, R. Croxford, K. Middelkoop, L.G. Bekker, C. Heiberg, J. Aploon, N. Killa, E. Fielder, T. Buhler). Johannesburg: The Wits Reproductive Health and HIV Institute, University of Witswatersrand, Hillbrow Health Precinct, Johannesburg (H. Rees, F. Venter, T. Palanee), Contract Laboratory Services, Johannesburg Hospital, Johannesburg (W. Stevens, C. Ingram, M. Majam, M. Papathanasopoulos). Kwazulu-Natal: HIV Prevention Unit, Medical Research Council, Durban (G. Ramjee, S. Gappoo, J. Moodley, A. Premrajh, L. Zako). Uganda: MRC/Uganda Virus Research Institute, Entebbe (H. Grosskurth, A. Kamali, P. Kaleebu, U. Bahemuka, J. Mugisha*, H.F. Njaj*). Spain: Hospital Clinic-IDIBAPS, University of Barcelona, Barcelona (J.M. Miro, M. López-Dieguez*, C. Manzardo, J.A. Arnaiz, T. Pumarola, M. Plana, M. Tuset, M.C. Ligero, M.T. García, T. Gallart, J.M. Gatell). UK and Ireland: Royal Sussex County Hospital, Brighton (M. Fisher, K. Hobbs, N. Perry, D. Pao, D. Maitland, L. Heald), St James's Hospital, Dublin (F. Mulcahy, G. Courtney, S. O’Dea, D. Reidy), Regional Infectious Diseases Unit, Western General Hospital and Genitourinary Department, Royal Infirmary of Edinburgh, Edinburgh (C. Leen, G. Scott, L. Ellis, S. Morris, P. Simmonds), Chelsea and Westminster Hospital, London (B. Gazzard, D. Hawkins, C. Higgs), Homerton Hospital, London (J. Anderson, S. Mguni), Mortimer Market Centre, London (I. Williams, N. De Esteban, P. Pellegrino, A. Arenas-Pinto, D. Cornforth*, J. Turner*) North Middlesex Hospital (J. Ainsworth, A. Waters), Royal Free Hospital, London (M. Johnson, S. Kinloch, A. Carroll, P. Byrne, Z. Cuthbertson), Barts \& the London NHS Trust, London (C. Orkin, J. Hand, C. De Souza), St Mary's Hospital, London (J. Weber, S. Fidler, E. Hamlyn, E. Thomson*, J. Fox*, K. Legg, S. Mullaney*, A. Winston, S. Wilson, P. Ambrose), Birmingham Heartlands Hospital, Birmingham (S. Taylor, G. Gilleran). Imperial College Trial \& DSMC Secretariat: S. Keeling, A. Becker. Imperial College DSMC Secretariat: C. Boocock. *Left the study team before the trial ended.
N.Y. was supported by the MRC; R.P. was supported by the Wellcome Trust, the Oxford Martin School and the NIHR Oxford BRC.

\section{Conflicts of interest}

There are no conflicts of interest.

\section{References}

1. Borrow $\mathrm{P}$, Lewicki $H$, Hahn BH, Shaw GM, Oldstone MB. Virusspecific CD8+ cytotoxic T-lymphocyte activity associated with control of viremia in primary human immunodeficiency virus type 1 infection. / Virol 1994; 68:6103-6110.

2. Koup RA, Safrit JT, Cao Y, Andrews CA, McLeod G, Borkowsky $W$, et al. Temporal association of cellular immune responses with the initial control of viremia in primary human immunodeficiency virus type 1 syndrome. / Virol 1994; 68:4650-4655.

3. Schmitz JE, Kuroda MJ, Santra S, Sasseville VG, Simon MA, Lifton MA, et al. Control of viremia in simian immunodeficiency virus infection by CD8 + lymphocytes. Science 1999; 283:857860.

4. Harrer T, Harrer E, Kalams SA, Elbeik T, Staprans SI, Feinberg $\mathrm{MB}$, et al. Strong cytotoxic $\mathrm{T}$ cell and weak neutralizing antibody responses in a subset of persons with stable nonprogressing HIV type 1 infection. AlDS Res Hum Retroviruses 1996; 12:585-592.

5. Rinaldo C, Huang XL, Fan ZF, Ding M, Beltz L, Logar A, et al. High levels of antihuman immunodeficiency virus type 1 (HIV-1) memory cytotoxic T-lymphocyte activity and low viral load are associated with lack of disease in HIV-1-infected longterm nonprogressors. J Virol 1995; 69:5838-5842.

6. Rowland-Jones S, Sutton J, Ariyoshi K, Dong T, Gotch F, McAdam S, et al. HIV-specific cytotoxic T-cells in HIV-exposed but uninfected Gambian women. Nat Med 1995; 1:59-64.

7. Phillips RE, Rowland-Jones S, Nixon DF, Gotch FM, Edwards JP, Ogunlesi $\mathrm{AO}$, et al. Human immunodeficiency virus genetic variation that can escape cytotoxic T cell recognition. Nature 1991; 354:453-459.

8. Borrow $\mathrm{P}$, Lewicki $\mathrm{H}$, Wei $\mathrm{X}$, Horwitz MS, Peffer $\mathrm{N}$, Meyers $\mathrm{H}$, et al. Antiviral pressure exerted by HIV-1-specific cytotoxic T lymphocytes (CTLs) during primary infection demonstrated by rapid selection of CTL escape virus. Nat Med 1997; 3:205-211.

9. Goulder PJ, Phillips RE, Colbert RA, McAdam S, Ogg G, Nowak $\mathrm{MA}$, et al. Late escape from an immunodominant cytotoxic T-lymphocyte response associated with progression to AIDS. Nat Med 1997; 3:212-217.

10. Kent SJ, Fernandez CS, Dale CI, Davenport MP. Reversion of immune escape HIV variants upon transmission: insights into effective viral immunity. Trends Microbiol 2005; 13:243-246.

11. Kaslow RA, Carrington M, Apple R, Park L, Munoz A, Saah AJ, et al. Influence of combinations of human major histocompatibility complex genes on the course of HIV-1 infection. Nat Med 1996; 2:405-411.

12. O'Brien SJ, Gao X, Carrington M. HLA and AIDS: a cautionary tale. Trends Mol Med 2001; 7:379-381.

13. Zhang $\mathrm{Y}$, Peng $\mathrm{Y}, \mathrm{Yan} \mathrm{H}, \mathrm{Xu} \mathrm{K}$, Saito $\mathrm{M}, \mathrm{Wu} \mathrm{H}$, et al. Multilayered defense in HLA-B51-associated HIV viral control. J Immunol 2011; 187:684-691.

14. Tomiyama H, Sakaguchi T, Miwa K, Oka S, Iwamoto A, Kaneko Y, et al. Identification of multiple HIV-1 CTL epitopes presented by HLA-B $* \mathbf{5 1 0 1}$ molecules. Hum Immunol 1999; 60:177-186.

15. Yusim K, Korber BTM, Brander C, Haynes BF, Koup R, Moore JP, et al. HIV molecular immunology. New Mexico: Los Alamos National Laboratory, Theoretical Biology and Biophysics; 2009

16. Leslie A, Kavanagh D, Honeyborne I, Pfafferott K, Edwards C, Pillay $\mathrm{T}$, et al. Transmission and accumulation of CTL escape variants drive negative associations between HIV polymorphisms and HLA. J Exp Med 2005; 201:891-902.

17. Mellors JW, Kingsley LA, Rinaldo CR Jr, Todd JA, Hoo BS, Kokka RP, et al. Quantitation of HIV-1 RNA in plasma predicts outcome after seroconversion. Ann Intern Med 1995; 122:573-579. 
18. Mellors JW, Rinaldo CR Jr, Gupta P, White RM, Todd JA, Kingsley LA. Prognosis in HIV-1 infection predicted by the quantity of virus in plasma. Science 1996; 272:11671170.

19. Fidler S, Oxenius A, Brady M, Clarke J, Cropley I, Babiker A, et al. Virological and immunological effects of short-course antiretroviral therapy in primary HIV infection. AIDS 2002; 16:2049-2054.

20. Duda A, Lee-Turner L, Fox J, Robinson N, Dustan S, Kaye S, et al. HLA-associated clinical progression correlates with epitope reversion rates in early human immunodeficiency virus infection. / Virol 2009; 83:1228-1239.

21. Guindon S, Gascuel O. A simple, fast, and accurate algorithm to estimate large phylogenies by maximum likelihood. Syst Biol 2003; 52:696-704.

22. Varela-Rohena A, Molloy PE, Dunn SM, Li Y, Suhoski MM, Carroll RG, et al. Control of HIV-1 immune escape by CD8 T cells expressing enhanced T-cell receptor. Nat Med 2008; 14:1390-1395.

23. Miura T, Brockman MA, Brumme ZL, Brumme CJ, Pereyra F, Trocha $A$, et al. HLA-associated alterations in replicationcapacity of chimeric NL4-3 viruses carrying gag-protease from elite controllers of human immunodeficiency virus type 1. J Virol 2009; 83:140-149.

24. Brumme ZL, Li C, Miura T, Sela J, Rosato PC, Brumme CJ, et al. Reduced replication capacity of NL4-3 recombinant viruses encoding reverse transcriptase-integrase sequences from HIV-1 elite controllers. I Acquir Immune Defic Syndr 2011; 56:100-108.

25. Kawashima Y, Pfafferott K, Frater J, Matthews P, Payne R, Addo $M$, et al. Adaptation of HIV-1 to human leukocyte antigen class I. Nature 2009; 458:641-645.
26. Bhattacharya $T$, Daniels M, Heckerman D, Foley B, Frahm N, Kadie $C$, et al. Founder effects in the assessment of HIV polymorphisms and HLA allele associations. Science 2007; 315:1583-1586.

27. Almeida JR, Price DA, Papagno L, Arkoub ZA, Sauce D, Bornstein $\mathrm{E}$, et al. Superior control of HIV-1 replication by CD8+ $T$ cells is reflected by their avidity, polyfunctionality, and clonal turnover. I Exp Med 2007; 204:2473-2485.

28. Payne RP, Kloverpris H, Sacha JB, Brumme Z, Brumme C, Buus $S$, et al. Efficacious early antiviral activity of HIV Gagand Pol-specific HLA-B 2705-restricted CD8+ T cells. I Virol 2010; 84:10543-10557.

29. Fidler S, SPARTAC Trial Investigators. The effect of short-course antiretroviral therapy in primary HIV infection: final results from an international randomised controlled trial; SPARTAC [abstract]. In: IAS 2011; Rome, Italy; 2011; WELBX06.

30. Propato A, Schiaffella E, Vicenzi E, Francavilla V, Baloni L, Paroli $M$, et al. Spreading of HIV-specific CD8+ T-cell repertoire in long-term nonprogressors and its role in the control of viral load and disease activity. Hum Immunol 2001; 62:561-576.

31. Leslie A, Price DA, Mkhize P, Bishop K, Rathod A, Day C, et al. Differential selection pressure exerted on HIV by CTL targeting identical epitopes but restricted by distinct HLA alleles from the same HLA supertype. I Immunol 2006; 177:4699-4708.

32. Kiepiela P, Ngumbela K, Thobakgale C, Ramduth D, Honeyborne I, Moodley E, et al. CD8+ T-cell responses to different HIV proteins have discordant associations with viral load. Nat Med 2007; 13:46-53.

33. Leslie AJ, Pfafferott KJ, Chetty P, Draenert R, Addo MM, Feeney $M$, et al. HIV evolution: CTL escape mutation and reversion after transmission. Nat Med 2004; 10:282-289. 